\title{
Outcomes with respect to extent of surgical resection for pediatric atypical teratoid rhabdoid tumors
}

\author{
Alexandra Richards ${ }^{1} \cdot$ Ronak Ved $^{1} \cdot$ Christopher Murphy $^{2} \cdot$ Dawn Hennigan $^{3} \cdot$ John-Paul Kilday $^{4} \cdot$ lan Kamaly-Asl ${ }^{2}$. \\ Conor Mallucci ${ }^{3} \cdot$ Imran Bhatti $^{1} \cdot$ Chirag Patel $^{1} \cdot$ Paul Leach $^{1}$
}

Received: 16 October 2019 /Revised: 16 October 2019 / Accepted: 17 December 2019 /Published online: 31 December 2019

(C) The Author(s) 2019

\begin{abstract}
Purpose To evaluate overall survival for atypical teratoid rhabdoid tumors (ATRTs) in relation to extent of surgical resection. Methods The neurosurgical tumor databases from three UK Pediatric centers (University Hospital of Wales, Alder Hey and Royal Manchester Children's Hospital) were analyzed. Patients with a diagnosis of ATRT were identified between 2000 and 2018. Data was collected regarding demographics, extent of resection, complications, and overall survival.

Results Twenty-four patients diagnosed with ATRT underwent thirty-eight operations. The age range was 20 days to 147 months (median 17.5 months). The most common location for the tumor was the posterior fossa (nine patients; $38 \%$ ). Six patients $(25 \%)$ underwent a complete total resection (CTR), seven (29\%) underwent a near total resection (NTR), eight (33.3\%) underwent a subtotal resection (STR), and three patients (12.5\%) had biopsy only. Two-thirds of patients who underwent a CTR are still alive, as of March 2019, compared to $29 \%$ in the NTR and $12.5 \%$ in the STR groups. Out of the thirty-eight operations, there were a total of twenty-two complications, of which the most common was pseudomeningocele $(27 \%)$. The extent of surgical resection $(p=0.021)$, age at surgery $(p=0.00015)$, and the presence of metastases at diagnosis $(0.015)$ significantly affected overall survival.

Conclusions Although these patients are a highly vulnerable group, maximal resection is recommended where possible, for the best chance of long-term survival. However, near total resections are likely beneficial when compared with subtotal resections and biopsy alone. Maximal surgical resection should be combined with adjuvant therapies for the best long-term outcomes.
\end{abstract}

Keywords Neuro-oncology $\cdot$ Central nervous system $\cdot$ Brain tumor $\cdot$ Neurosurgery

\section{Introduction}

Atypical teratoid rhabdoid tumors (ATRTs) are rare, embryonal malignancies found predominantly in infancy. They represent $1-2 \%$ of childhood central nervous system (CNS)

Alexandra Richards

richardsAE4@cardiff.ac.uk

1 Department of Pediatric Neurosurgery, University Hospital of Wales, Cardiff CF14 4XW, UK

2 Department of Pediatric Neurosurgery, Royal Manchester Children's Hospital, Manchester M13 9WL, UK

3 Department of Pediatric Neurosurgery, Alder Hey Children's Hospital, Liverpool L14 5AB, UK

4 Department of Pediatric Neuro-Oncology, Children's Brain Tumor Research Network, Royal Manchester Children's Hospital, Manchester M13 9WL, UK tumors, with a peak incidence in children less than 3 years of age (10-15\%) [24]. They are characterized by bi-allelic loss of function mutations in typically $S M A R C B 1$, or rarely SMARCA4, encoding for sub-units of the SWI/SNF chromatin remodeling complex $[13,19,31]$. Previously, ATRTs were labeled as primitive neuroectodermal tumor, choroid plexus tumor, or medulloblastoma, until their distinct morphology was identified in 1978 [3]. These tumors were finally given their own formal classification by the World Health Organization in 2000, which now requires molecular confirmation of the characteristic mutations [16, 23, 24, 27]. Despite developments in cancer research, the prognosis of ATRTs remains poor, with a median survival reported between 6 and 12 months [7-9, 12, 27, 29]. ATRTs are mostly managed with a combination of surgery followed by adjuvant oncological treatment. However, there is still significant ambiguity in the literature regarding optimal treatment. The aim of this study is to evaluate the efficacy of surgical resection in relation to survival for children with ATRTs. 


\section{Materials and methods}

A retrospective analysis of three prospectively collected UK pediatric neurosurgical databases was performed (University Hospital of Wales, Alder Hey Hospital and The Royal Manchester Children's Hospital). Patients with a confirmed histological diagnosis of ATRT were identified since January 2000. Case notes of these patients were reviewed along with all their radiology, and a database was compiled to collate data such as location of tumor, extent of surgical resection, survival, and postoperative complications.

Patients were grouped according to extent of surgical resection of their tumor. Cases that underwent more than one operation were categorized with their best extent of surgical resection. Complete total resection (CTR) is defined as no residual tumor seen on postoperative imaging [21]. Near total resection (NTR) is described as more than 90\% tumor removal and subtotal resection (STR) is within the range of $10 \%$ to $90 \%$ of tumor resected. "Biopsy" was defined as any operation with less than $10 \%$ tumor resection. All grades of resection were quantitatively confirmed with postsurgical magnetic resonance imaging and volumetric studies with the neuroradiologists.

\section{Statistical analysis}

Statistical analyses were computed using IBM SPSS Statistics (Version 25; 2019). Survival analysis was performed by the Kaplan-Meier method with significance values for comparisons established by the log rank test. Overall survival (OS) was defined in years from the date of tumor diagnosis to the date of death or censorship if alive. A $p$ value of less than 0.05 was considered statistically significant. Multivariate analysis was carried out using cox regression.

\section{Results}

Twenty-four patients diagnosed with ATRTs underwent thirtyeight operations in total. The age range was from 20 days to 147 months (median: 17.5 months). Twelve (50\%) were female and twelve (50\%) were male. Seventeen patients had one operation, four patients had two, and one patient each had three, four, and six operations, respectively. The most common location for the tumor was the posterior fossa, which included nine patients (38\%). Of these, one-third had extension into the fourth ventricle (Fig. 1). Five patients $(21 \%)$ had metastases at initial presentation.

In our study, six patients $(25 \%)$ underwent a CTR, and seven (29\%) underwent an NTR. Eight patients (33.3\%) had STR, and three patients (12.5\%) had biopsy only (Fig. 2).

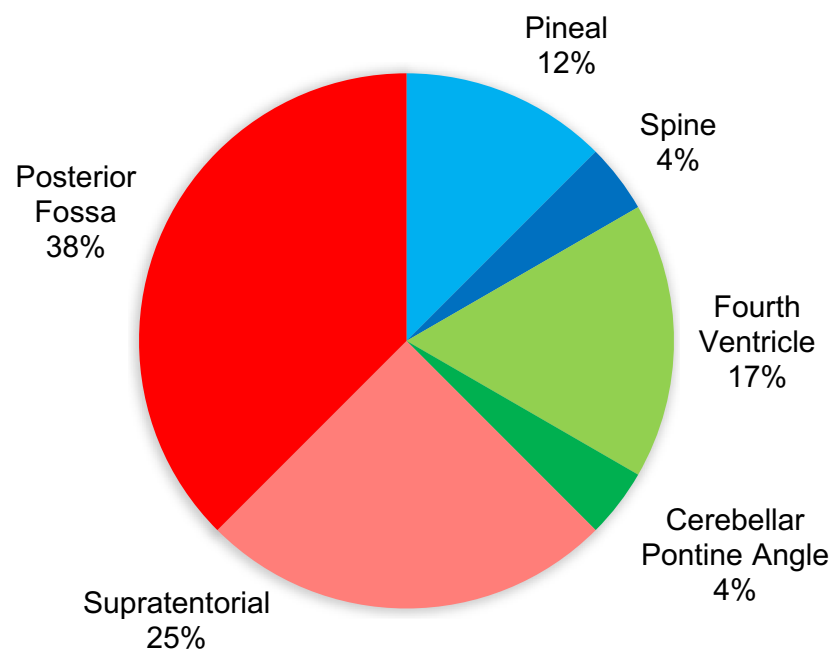

Fig. 1 The primary locations of ATRTs in our cohort

\section{Complete total resection group}

Four patients (66.6\%) had initial CTR and are still alive as of March 2019 (7 to 158 months from surgery; group median 19.5 months). Two out of six (33.3\%) are now deceased.

\section{Near total resection group}

Of the seven patients who underwent NTR, two patients (29\%) remain alive (85 and 127 months from surgery; group median 6 months) and five (71\%) are deceased.

\section{Subtotal resection group}

In the STR group, one patient (12.5\%) is alive (44 months from surgery) and seven (87.5\%) are deceased.

\section{Biopsy only group}

In the biopsy group, one patient remains alive (33.3\%) (4 months from surgery). The other two patients $(66.6 \%)$ are

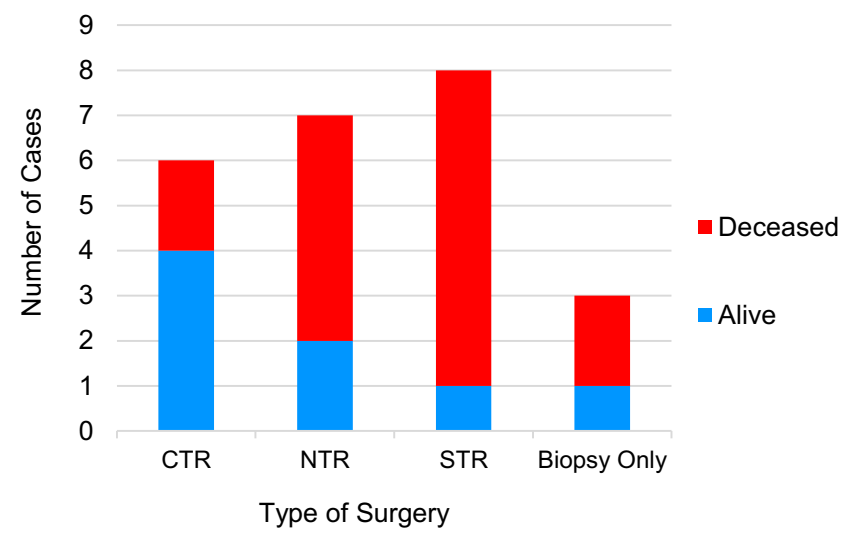

Fig. 2 Overall survival in patients undertaking surgical procedures 
deceased. The median survival for the STR and BO groups combined is 6 months.

\section{Survival analysis}

Univariate analysis was carried out to ascertain variables which may influence survival in the study cohort. Overall survival within the CTR group was significantly higher compared to the NTR and STR groups ( $p=0.048$, Fig. 3). Concordantly, survival was significantly worse in STR groups when compared to all patients who underwent near or complete total resections ( $p=0.021$; Fig. 4). Survival was also significantly worse in patients presenting under the age of one $(p=0.00015)$ and those who had metastases at initial diagnosis ( $p=0.015$; Figs. 5 and 6 ).

Multivariate analysis using the cox regression method was conducted. Older age was still significantly associated with longer survival $(p=0.008)$. While extent of resection still showed a trend toward significance, $(p=0.125)$ the presence of metastases was not significantly associated with an effect on survival in this analysis $(p=0.316)$.

\section{Neurosurgical complications}

Within the thirty-eight studied operations, there were twentytwo complications (Table 1). The most common complication was pseudomeningocele (six patients; $25 \%$ ). Eight out of the twenty-four patients $(33.3 \%)$ required a ventriculoperitoneal shunt for hydrocephalus.

Twenty-two patients (96\%) received adjuvant chemotherapy (CMT) as per the European Rhabdoid Tumor Registry (EU-RHAB) 2007 Protocol. Eleven patients (46\%) underwent radiotherapy (RT) postoperatively. Twelve patients received triple modality therapy (surgery, chemotherapy and radiotherapy) - of which 50\% have survived (Fig. 7).

\section{Discussion}

ATRT is a highly malignant neoplasm associated with a poor prognosis. It is primarily found in infancy; however, it has been diagnosed both antenatally and in adults [1, 10, 17]. Due to the lack of large prospective studies regarding ATRT, there is still uncertainty regarding the optimal treatment for these children and therefore, management strategies vary. It is, however, generally accepted that these patients need a combination of surgical resection followed by adjuvant chemotherapy (as per the European Rhabdoid Tumor Registry 2007 Protocol) plus or minus radiotherapy, according to age at presentation [7, 8, 27].

The majority of studies have been unable to quantify the significance of extent of surgical resection with regard to long-term survival. However, others have inferred that surgery appears to influence prognosis. Hilden et al. reported increased event-free survival of 14 months in patients who underwent a CTR compared to 9.25 months for those who had a STR [17]. Athale et al. identified an overall survival of 21.3 months for a CTR in contrast to 12.3 months for a STR and 10.2 months for biopsy alone [2]. However, these authors also state that, with a postoperative mortality rate of $4 \%$, surgery may not be beneficial above receiving chemotherapy alone. Conversely, more recent work by Biswas et al. and Lafay-Cousin et al. suggest that CTR correlates with an increased 2-year survival from $21.7 \%$ (STR) to $60 \%$ (CTR) [7, 22]. This is similar to the findings of the present study, which identified a trend toward increased survival with maximal resection (66.6\% compared to $29 \%$ and $12.5 \%$ in the NTR and STR groups, respectively; Table 1).

This study identified that extent of resection, older age, and the presence of metastases, at presentation, were significantly associated with overall survival in univariate analysis. This corroborates the results of other case series within the literature which also identified extent of
Fig. 3 Kaplan-Meier curves comparing survival of patients after CTR, NTR, and STR. Logrank test identified that greater resection was significantly associated with increased survival $(p=0.048)$

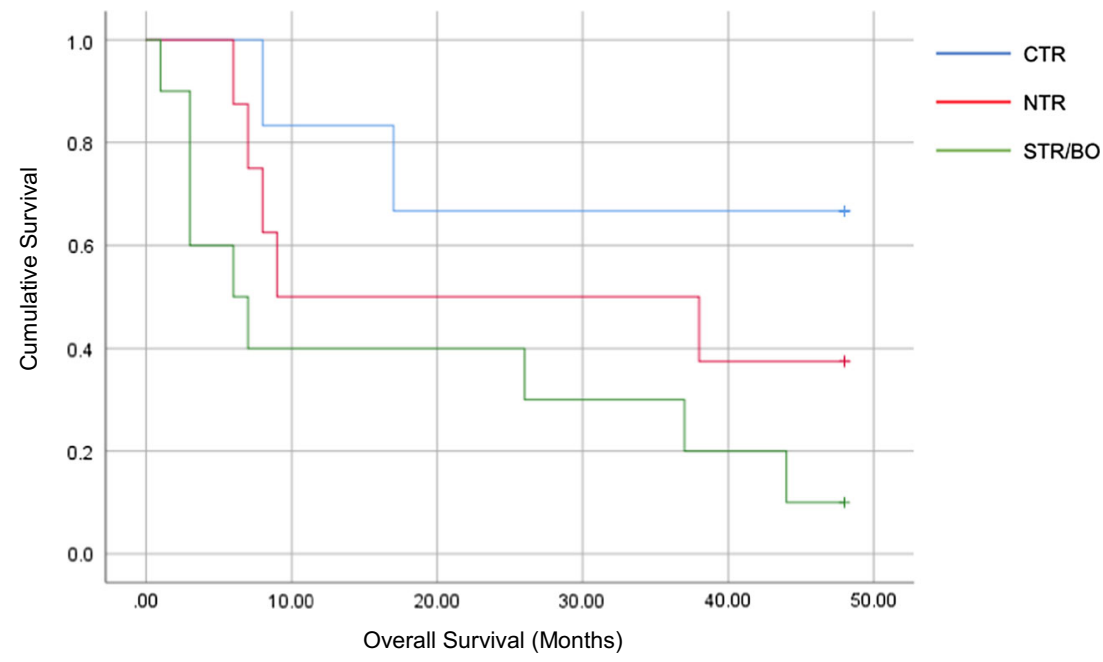


Fig. 4 Kaplan-Meier curves comparing survival of patients after STR or Biopsy verses all other more extensive surgeries, (NTR or CTR together). Log-rank test identified that subtotal resection was significantly associated with reduced survival $(p=0.021)$

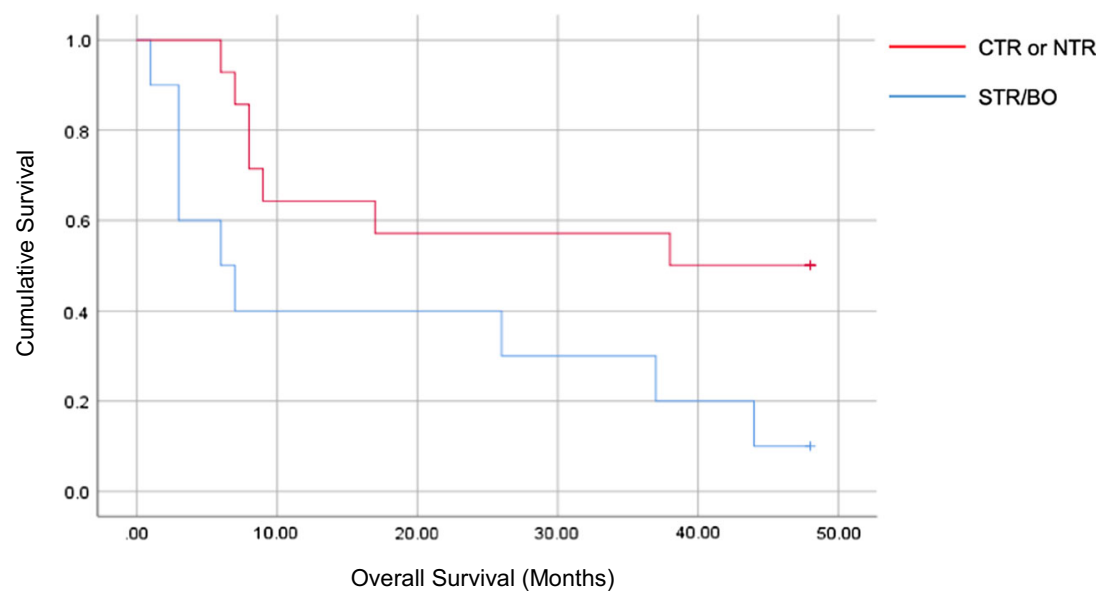

resection with increased survival $[7,15,17,18,22,29]$. Previous studies have estimated that $30 \%$ of patients will have metastatic disease at presentation, of which there is a higher incidence in patients less than 3 years old $[12,29]$. Dufour et al. identified that patients younger than 2 years old had a poorer 1 year overall survival in univariate analysis (34\% compared to $55 \%$ in the younger and older groups, respectively) [12]. Likewise, Tekautz et al. reported superior 2-year overall survival in patients older than 3 years old $(89 \% \pm 17 \%)$ compared to the younger cohort $(17 \% \pm 9 \%)$ [30].This is possibly due to an increased chance of CTR, ability to undergo radiotherapy plus a lower chance of metastases at presentation.

In subsequent multivariate analysis, younger age remained a significant factor for mortality, while extent of resection demonstrated a trend toward significance. Metastases at presentation were not associated with a survival effect in multivariate testing. This may be attributed to the present study being underpowered to fully detect the impact of resection and metastases upon survival during a multivariate analysis, and thus a larger cohort analysis may subsequently confirm the extent to which resection type impacts upon survival. It may also be possible that the effect of younger age at surgery is of such a magnitude that it contributes to the impact of surgical resection and metastases during univariate analyses. While many studies highlight the significance of maximal resection in terms of survival, several report that extent of resection is not significant when matched with other prognostic indicators $[2,9,12,17]$. These incongruities are likely due to the lack of large, prospective studies needed to evaluate prognosis and warrants further exploration.

Some studies have suggested the importance of subsequent surgeries to obtain maximal resection, agreeing with the verdict that CTR is a positive prognostic indictor. Von Hoff et al. noted that four out of eighteen $(22.2 \%)$ patients in their case series underwent a second surgery to achieve complete resection of their ATRT and thus recommend additional procedures, where possible, for increased event-free survival [32]. Furthermore, Fidani et al. reported that surgical resection may be beneficial even in relapsed patients, emphasizing the importance of re-do surgical interventions [14]. In our cohort, seven patients $(29 \%)$ required more than one surgical
Fig. 5 Kaplan-Meier curves comparing survival of patients when operated at age $<1$ yr or $>$ 1 yr. Log-rank test identified that the older age group was significantly associated with greater overall survival, ( $p=$ 0.00015)

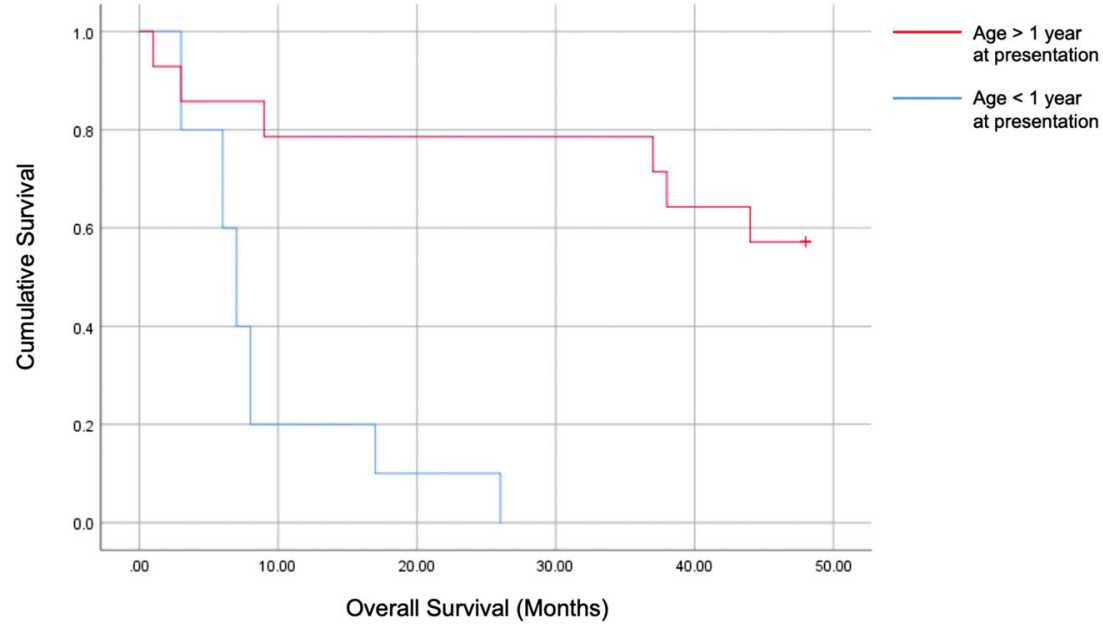


Fig. 6 Kaplan-Meier curves comparing survival of patients who had metastases at diagnosis with those who did not have evidence of metastatic disease. Log-rank test identified that the absence of metastases at diagnosis was significantly associated with increased survival $(p=0.015)$

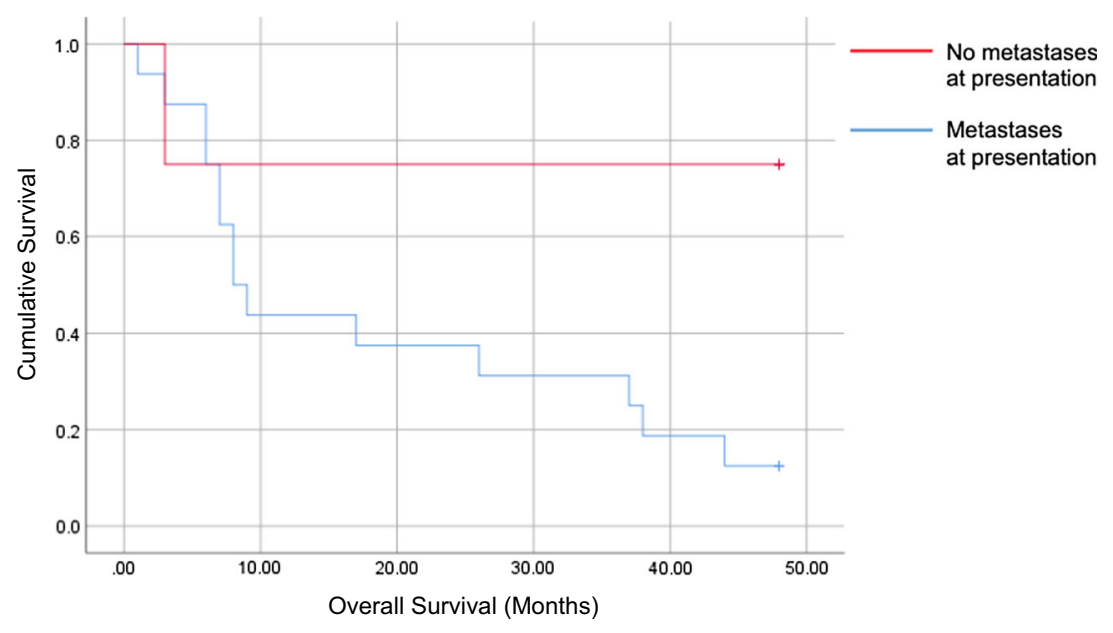

procedure. Two patients within this sub-cohort had confirmed CTR. Despite this, both of these patients are deceased. Re-do surgery is challenging and remains of uncertain benefit; therefore, its use should be considered on a case-by-case basis.

Although CTR is favorable for survival, it is not always feasible to achieve this. Only $25 \%$ of patients in our study underwent a CTR. There did not appear to be a correlation between the location of the tumor and extent of surgical resection in this study. Postoperative radiotherapy was offered to $83 \%$ of patients in the CTR group compared to $39 \%$ in the non-CTR group. This difference could be due to the fact that the non-CTR group consists of a younger cohort, to whom treating clinicians may be reticent to give radiotherapy.

Chi et al. concurs that CTR is favorable, with a 2-year overall survival of $91 \%$, although, their report concluded that an aggressive, multimodal regimen is the optimum for long-term survival [11]. Upon reviewing data from the National Cancer Institute, Buscariollo et al. informed that they did not observe any consistency with the extent of surgery in relation to overall survival outcomes so have implicated that surgical resection alone is not adequate [9]. This is further elucidated by Rorke et al. who reported

Table 1 Neurosurgical complications

\begin{tabular}{ll} 
Postoperative complication & Number of patients with this complication \\
\hline Pseudomeningocele & 6 \\
Subdural effusion & 1 \\
CSF leak & 5 \\
Neurological deficits & 3 \\
Posterior fossa syndrome & 3 \\
Hyponatremia & 2 \\
Subdural hematoma & 1 \\
Meningitis & 1 \\
\hline
\end{tabular}

that nine children died postoperatively after not receiving any adjuvant therapy, providing further evidence for the need for chemotherapy plus or minus radiotherapy after surgical resection [28]. Additionally, Ren et al. found improved 2-year survival outcomes of $57.1 \%$ using a combination of therapies (including gamma-knife surgery) in comparison to $18.9 \%$ with other therapies alone [26]. In our report, twelve patients received adjuvant chemotherapy and radiotherapy, of which $50 \%$ have survived. This is the highest overall survival in all of our treatment groups (Fig. 7), which supports the findings of several other reports within the literature $[8,11,14,15,18,25,27]$.

Germline mutations of SMARCB1/SMARCA4 have also been associated with poorer survival $[10,13,27,28]$, while newer evidence purports an association with molecular subgrouping [17,31]. Germline mutations of SMARCB1 appear to predispose patients to synchronous rhabdoid tumors within and out-with the CNS [3, 4]. Numerous reports have observed that these patients have a worse prognosis $[3-6,10,16,20]$. Therefore, identification of genetic profiles and phenotypes of ATRTs remains an unmet research need to develop an additional prognostication tool.

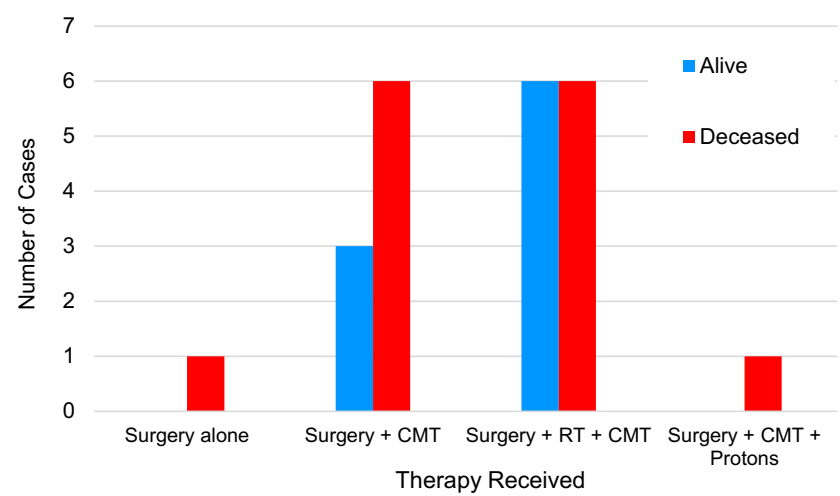

Fig. 7 Outcomes for patients receiving different combinations of therapy for ATRTs 


\section{Conclusion}

This is a highly vulnerable group of patients undergoing complex neurosurgical procedures with high risk of surgical morbidity. Although ATRTs have a poor prognosis, we recommend maximal resection for the best chance of long-term survival. However, near total resection is likely beneficial when compared with subtotal resection and biopsy alone. Maximal surgical resection should be combined with adjuvant therapies for the best long-term outcomes.

Author contributions Data collection was performed by AR, CM, DH, and J-PK. Statistical analysis was performed by RV and J-PK. The manuscript was written by AR, RV, and PL. All authors commented on previous versions. All authors read and approved the final manuscript.

\section{Compliance with ethical standards}

Conflict of interest All authors declare that they have no conflicts of interest.

Open Access This article is licensed under a Creative Commons Attribution 4.0 International License, which permits use, sharing, adaptation, distribution and reproduction in any medium or format, as long as you give appropriate credit to the original author(s) and the source, provide a link to the Creative Commons licence, and indicate if changes were made. The images or other third party material in this article are included in the article's Creative Commons licence, unless indicated otherwise in a credit line to the material. If material is not included in the article's Creative Commons licence and your intended use is not permitted by statutory regulation or exceeds the permitted use, you will need to obtain permission directly from the copyright holder. To view a copy of this licence, visit http://creativecommons.org/licenses/by/4.0/.

\section{References}

1. Asmaro K, Arshad M, Massie L, Griffith B, Lee I (2019) Sellar atypical teratoid/Rhabdoid tumor presenting with subarachnoid and intraventricular hemorrhage. World Neurosurg 123:e31-e38

2. Athale UH, Duckworth J, Odame I, Barr R (2009) Childhood atypical teratoid rhabdoid tumor of the central nervous system. J Pediatr Hematol Oncol 31:651-663. https://doi.org/10.1097/MPH. 0b013e3181b258a9

3. Beckwith J, Palmer N (1978) Histopathology and prognosis of Wilms tumor results from the first national Wilms' tumor study. Cancer 41:1937-1948

4. Biegel JA (2006) Molecular genetics of atypical teratoid/rhabdoid tumor. Neurosurg Focus 20:E11

5. Biegel JA, Zhou JY, Rorke LB, Stenstrom C, Wainwright LM, Fogelgren B (1999) Germ-line and acquired mutations of INI1 in atypical teratoid and rhabdoid tumors. Cancer Res 59:74-79

6. Biegel JA, Tan L, Zhang F, Wainwright L, Russo P, Rorke LB (2002) Alterations of the hSNF5/INI1 gene in central nervous system atypical teratoid/rhabdoid tumors and renal and extrarenal rhabdoid tumors. Clin Cancer Res 8:3461-3467

7. Biswas A, Julka PK, Bakhshi S, Suri A, Rath GK (2015) Intracranial atypical teratoid rhabdoid tumor: current management and a single institute experience of 15 patients from
North India. Acta Neurochir 157:589-596. https://doi.org/10. 1007/s00701-015-2355-2

8. Biswas A, Kashyap L, Kakkar A, Sarkar C, Julka PK (2016) (2016) atypical teratoid/rhabdoid tumors: challenges and search for solutions. Cancer Manag Res 8:115-125

9. Buscariollo DL, Park HS, Roberts KB, Yu JB (2012) Survival outcomes in atypical teratoid rhabdoid tumor for patients undergoing radiotherapy in a surveillance, epidemiology, and end results analysis. Cancer 118:4212-4219. https://doi.org/10.1002/cncr.27373

10. Chan V, Marro A, Findlay JM, Schmitt LM, Das S (2018) A systematic review of atypical teratoid rhabdoid tumor in adults. Front Oncol 8:567. https://doi.org/10.3389/fonc.2018.00567

11. Chi SN, Zimmerman MA, Yao X, Cohen KJ, Burger P, Biegel JA, Rorke-Adams LB, Fisher MJ, Janss A, Mazewski C, Goldman S, Manley PE, Bowers DC, Bendel A, Rubin J, Turner CD, Marcus KJ, Goumnerova L, Ullrich NJ, Kieran MW (2009) Intensive multimodality treatment for children with newly diagnosed CNS atypical teratoid rhabdoid tumor. J Clin Oncol 27:385-389. https://doi.org/10.1200/JCO.2008.18.7724

12. Dufour C, Beaugrand A, Le Deley MC, Bourdeaut F, André N, Leblond P, Bertozzi AI, Frappaz D, Rialland X, Fouyssac F, Edan C, Grill J, Quidot M, Varlet P (2012) Clinicopathologic prognostic factors in childhood atypical teratoid and rhabdoid tumor of the central nervous system: a multicenter study. Cancer 118:38123821. https://doi.org/10.1002/cncr.26684

13. Erkek S, Johann PD, Finetti MA, Drosos Y, Chou HC, Zapatka M, Sturm D et al (2019) Comprehensive analysis of chromatin states in atypical Teratoid/Rhabdoid tumor identifies diverging roles for SWI/SNF and Polycomb in gene regulation. Cancer Cell 35(1): 95-110.e8. https://doi.org/10.1016/j.ccell.2018.11.014

14. Fidani P, De Ioris MA, Serra A, De Sio L, Ilari I, Cozza R, Boldrini R, Milano GM, Garrè ML, Donfrancesco A (2009) A multimodal strategy based on surgery, radiotherapy, ICE regimen and high dose chemotherapy in atypical teratoid/rhabdoid tumours: a single institution experience. J Neuro-Oncol 92:177-183. https://doi.org/10. 1007/s11060-008-9750-y

15. Fossey M, Li H, Afzal S, Carret AS, Eisenstat DD, Fleming A, Hukin J, Hawkins C, Jabado N, Johnston D, Brown T, Larouche V, Scheinemann K, Strother D, Wilson B, Zelcer S, Huang A, Bouffet E, Lafay-Cousin L (2017) Atypical teratoid rhabdoid tumor in the first year of life: the Canadian ATRT registry experience and review of the literature. J Neuro-Oncol 132:155-162. https://doi. org/10.1007/s11060-016-2353-0

16. Gonzales M (2001) The 2000 World Health Organization classification of tumours of the nervous system. J Clin Neurosci 8:1-3

17. Hilden JM, Meerbaum S, Burger P, Finlay J, Janss A, Scheithauer BW, Walter AW, Rorke LB, Biegel JA (2004) Central nervous system atypical teratoid/rhabdoid tumor: results of therapy in children enrolled in a registry. J Clin Oncol 22:2877-2884. https://doi. org/10.1200/JCO.2004.07.073

18. Howes TL, Buatti JM, O'Dorisio MS, Kirby PA, Ryken TC (2005) Atypical teratoid/rhabdoid tumor case report: treatment with surgical excision, radiation therapy, and alternative medicines. J NeuroOncol 72:85-88. https://doi.org/10.1007/s11060-004-3120-1

19. Johann PD, Erkek S, Zapatka M, Kerl K, Buchhalter I, Hovestadt V, Jones DTW, Sturm D, Hermann C, Segura Wang M, Korshunov A, Rhyzova M, Gröbner S, Brabetz S, Chavez L, Bens S, Gröschel S, Kratochwil F, Wittmann A, Sieber L, Geörg C, Wolf S, Beck K, Oyen F, Capper D, van Sluis P, Volckmann R, Koster J, Versteeg R, von Deimling A, Milde T, Witt O, Kulozik AE, Ebinger M, Shalaby T, Grotzer M, Sumerauer D, Zamecnik J, Mora J, Jabado N, Taylor MD, Huang A, Aronica E, Bertoni A, Radlwimmer B, Pietsch T, Schüller U, Schneppenheim R, Northcott PA, Korbel JO, Siebert R, Frühwald MC, Lichter P, Eils R, Gajjar A, Hasselblatt M, Pfister SM, Kool M (2016) Atypical teratoid/rhabdoid tumors are comprised of three epigenetic subgroups with distinct enhancer 
landscapes. Cancer Cell 29(3):379-393. https://doi.org/10.1016/j. ccell.2016.02.001

20. Kordes U, Gesk S, Frühwald MC, Graf N, Leuschner I, Hasselblatt M, Jeibmann A, Oyen F, Peters O, Pietsch T, Siebert R, Schneppenheim R (2010) Clinical and molecular features in patients with atypical teratoid rhabdoid tumor or malignant rhabdoid tumor. Genes Chromosom Cancer 49:176-181. https://doi.org/10. $1002 /$ gcc. 20729

21. Kramm C, Wagner S, Van-Gool S, Schmid H et al (2006) Improved survival after gross total resection of malignant Gliomas in pediatric patients from the HIT-GBM studies. Anticancer Res 26:3773-3780

22. Lafay-Cousin L, Hawkins C, Carret AS, Johnston D, Zelcer S, Wilson B, Jabado N, Scheinemann K, Eisenstat D, Fryer C, Fleming A, Mpofu C, Larouche V, Strother D, Bouffet E, Huang A (2012) Central nervous system atypical teratoid rhabdoid tumours: the Canadian pediatric brain tumour consortium experience. Eur J Cancer 48:353-359. https://doi.org/10.1016/j.ejca.2011.09. 005

23. Louis DN, Perry A, Reifenberger G, von Deimling A, FigarellaBranger D, Cavenee WK, Ohgaki H, Wiestler OD, Kleihues P, Ellison DW (2016) The 2016 World Health Organization classification of tumors of the central nervous system: a summary. Acta Neuropathol 131(6):803-820

24. Packer RJ, Biegal JA, Blaney S, Finlay J, Geyer JR, Heideman R, Hilden J, Janss AJ, Kun L, Vezina G, Rorke LBSM (2002) Atypical Teratoid/Rhabdoid tumor of the central nervous system: report on workshop. J Pediatr Haematol 24:337-342

25. Quinn TJ, Almahariq MF, Siddiqui ZA et al (2019) Trimodality therapy for atypical teratoid/rhabdoid tumor is associated with improved overall survival: a surveillance, epidemiology, and end results analysis. Pediatr Blood Cancer:e27969. https://doi.org/10. 1002/pbc.27969

26. Ren Y-M, Wu X, You C, Zhang YK, Li Q, Ju Y (2018) Multimodal treatments combined with gamma knife surgery for primary atypical teratoid/rhabdoid tumor of the central nervous system: a singleinstitute experience of 18 patients. Childs Nerv Syst 34:627-638. https://doi.org/10.1007/s00381-017-3688-3

27. Richardson EA, Ho B, Huang A (2018) Atypical Teratoid Rhabdoid tumour: from tumours to therapies. J Korean Neurosurg Soc 61(3): 302-311. https://doi.org/10.3340/jkns.2018.0061

28. Rorke LB, Packer RJ, Beigal JA (1996) Central nervous system atypical teratoid/rhabdoid tumors of infancy and childhood: definition of an entity. J Neurosurg 85:56-65

29. Strother D (2005) Atypical teratoid rhabdoid tumors of childhood: diagnosis, treatment and challenges. Expert Rev Anticancer Ther 5: 905-915
30. Tekautz TM, Fuller CE, Blaney S, Fouladi M, Broniscer A, Merchant TE, Krasin M, Dalton J, Hale G, Kun LE, Wallace D, Gilbertson RJ, Gajjar A (2005) Atypical teratoid/rhabdoid tumors (ATRT): improved survival in children 3 years of age and older with radiation therapy and high-dose Alkylator-based chemotherapy. J Clin Oncol 23:1491-1499. https://doi.org/10.1200/JCO.2005.05.187

31. Torchia J, Golbourn B, Feng S, Ho KC, Sin-Chan P, Vasiljevic A, Norman JD, Guilhamon P, Garzia L, Agamez NR, Lu M, Chan TS, Picard D, de Antonellis P, Khuong-Quang DA, Planello AC, Zeller C, Barsyte-Lovejoy D, Lafay-Cousin L, Letourneau L, Bourgey M, Yu M, Gendoo DMA, Dzamba M, Barszczyk M, Medina T, Riemenschneider AN, Morrissy AS, Ra YS, Ramaswamy V, Remke M, Dunham CP, Yip S, Ng HK, Lu JQ, Mehta V, Albrecht S, Pimentel J, Chan JA, Somers GR, Faria CC, Roque L, Fouladi M, Hoffman LM, Moore AS, Wang Y, Choi SA, Hansford JR, Catchpoole D, Birks DK, Foreman NK, Strother D, Klekner A, Bognár L, Garami M, Hauser P, Hortobágyi T, Wilson B, Hukin J, Carret AS, van Meter T, Hwang EI, Gajjar A, Chiou SH, Nakamura H, Toledano H, Fried I, Fults D, Wataya T, Fryer C, Eisenstat DD, Scheinemann K, Fleming AJ, Johnston DL, Michaud J, Zelcer S, Hammond R, Afzal S, Ramsay DA, Sirachainan N, Hongeng S, Larbcharoensub N, Grundy RG, Lulla RR, Fangusaro JR, Druker H, Bartels U, Grant R, Malkin D, McGlade C, Nicolaides T, Tihan T, Phillips J, Majewski J, Montpetit A, Bourque G, Bader GD, Reddy AT, Gillespie GY, Warmuth-Metz M, Rutkowski S, Tabori U, Lupien M, Brudno M, Schüller U, Pietsch T, Judkins AR, Hawkins CE, Bouffet E, Kim SK, Dirks $\mathrm{PB}$, Taylor MD, Erdreich-Epstein A, Arrowsmith CH, de Carvalho DD, Rutka JT, Jabado N, Huang A (2016) Integrated (epi)-genomic analyses identify subgroup-specific therapeutic targets in CNS rhabdoid tumors. Cancer Cell 30(6):891-908. https:// doi.org/10.1016/j.ccell.2016.11.003

32. Von Hoff K, Hinkes B, Dannenmann-Stern E, Von Bueren AO, Warmuth-Metz M, Soerensen N, Emser A, Zwiener I, Schlegel PG, Kuehl J, Frühwald MC, Kortmann RD, Pietsch T, Rutkowski S (2011) Frequency, risk-factors and survival of children with atypical teratoid rhabdoid tumors (AT/RT) of the CNS diagnosed between 1988 and 2004, and registered to the German HIT database. Pediatr Blood Cancer 57:978985. https://doi.org/10.1002/pbc.23236

Publisher's note Springer Nature remains neutral with regard to jurisdictional claims in published maps and institutional affiliations. 